\title{
Democratização das mídias e educação
}

\author{
Maria Cristina Castilho Costa \\ Livre-Docente em Ciências da Comunicação pela Escola de Comunicações e Artes da \\ Universidade de São Paulo (USP). Professora Titular em Comunicação e Cultura da USP, \\ Coordenadora do curso Censura e Liberdade de Expressão em Debate. \\ E-mail: criscast@usp.br
}

Resumo: Este texto trata dos obstáculos que impedem o público em geral diferenciar mensagens e informações da realidade que o cerca. Para isso, trabalhamos com duas ideias básicas: de um lado, os avanços da democracia no mundo ocidental e, de outro, o desenvolvimento dos meios de comunicação e a instituição da sociedade mediática. Apresenta-se o conflito que existe entre os mecanismos políticos republicanos e a liberdade de expressão, assim como entre os interesses do mercado e a informação. Analisando historicamente diferentes etapas desses conflitos, propõe-se, na sociedade globalizada e conectada pela comunicação em rede, a luta pela democratização das mídias como forma de libertar o público da Caverna de Platão do mundo contemporâneo.

Palavras-chave: comunicação; democracia; liberdade; informação.
Abstract: This text approaches the obstacles that prevent the general public from differentiating messages and information from the reality. For such purpose, we work with two basic ideas: on the one hand, the advances of democracy in the Western world and, on the other hand, the development of the media and the establishment of media society. We present the conflict between republican political mechanisms and freedom of speech, and between market interests and information. By historically analyzing different stages of these conflicts, this article proposes, in a globalized society connected by network communication, the fight for the democratization of the media as a way to free the public from Plato's Cave of the contemporary world.

Keywords: communication, democracy freedom, information 


\section{INTRODUÇÃO - ENTRE OS GREGOS}

Para abordarmos o que entendemos por democratização das mídias e sua importância na educação, vamos começar este texto por uma história muito antiga e de conhecimento de todos, mas que continua servindo de referência para os estudiosos da linguagem e das mediações. Trata-se do mito da caverna, atribuído a Sócrates e divulgado por Platão, na Antiguidade, uma metáfora ou alegoria que propõe o seguinte dilema: alguns homens foram aprisionados desde a infância em uma caverna, não conseguindo se mover por estarem acorrentados a uma parede, de costas para a entrada da caverna e de frente para a parede contrária. Tudo que eles podiam ver do que acontecia no mundo fora da caverna eram imagens projetadas na parede em frente, em sua maioria, figuras aterrorizantes que os enchiam de medo.

Um dia, entretanto, um dos acorrentados consegue se livrar e ascender ao mundo exterior e se surpreende ao deparar com uma fogueira em frente, na qual eram colocadas estátuas cuja sombra se projetava no fundo da caverna. Tomando consciência de que as imagens aterrorizantes não passavam de engano ou ilusão, esse homem tenta voltar para dentro da caverna para alertar os demais da manipulação de que eram vítimas. Os prisioneiros, entretanto, não acreditam no testemunho do homem e continuam acorrentados ao fundo da caverna. Esse mito, também chamado de "Alegoria da Caverna”, publicado na obra República1, tinha a intenção de alertar os atenienses para os equívocos de que eram vítimas, por sua resistência em sair do conforto de seus preconceitos e seus hábitos e ouvir ideias diferentes e aparentemente revolucionárias. Podemos dizer que se trata de uma autodefesa - depois da execução de Sócrates, de quem fora discípulo, Platão temia o julgamento de seus contemporâneos e, com o Mito da Caverna, alerta para o perigo de se acreditar cegamente naquilo que é mera alucinação.

À época, não havia os meios de comunicação de massa nem as tecnologias de construção de imagens, portanto, não era a eles que Platão se referia, mas à dificuldade que temos de duvidarmos de nossas falsas e ilusórias impressões ou interpretações da realidade. Mas, como o desenvolvimento dos meios de comunicação não fizeram senão multiplicar os meios de criação de imagens intencionalmente fabricadas para nos transmitirem determinadas visões de mundo, o mito da Caverna de Platão tem sido regularmente lembrado pelos cientistas da comunicação para alertarem sobre a necessidade de uma visão cética e crítica diante dos discursos mediáticos.

No caso do nosso texto, a importância de iniciá-lo pela referência à Alegoria da Caverna se deve aos princípios da cultura grega e da vida política de Atenas, em um período tão relevante para nós até a atualidade que é a democracia. Isto é, o Mito da Caverna só faz sentido e ganha importância se pensarmos em quanto era surpreendente e inédito que, no século VI a.C., uma sociedade antiga pensasse que imagens e realidades poderiam ser produzidas por seres humanos e não por divindades. O que emociona na proposta de Platão é pensarmos que, já nessa época, proclamava-se a possibilidade do ser humano alcançar a verdade e desfazer-se de falsas e enganosas visões de mundo. E que Sócrates e
1. PLATÃO. A Alegoria da caverna: A Republica, 514a-517c. In: MARCONDES, Danilo. Textos básicos de Filosofia: dos Présocráticos a Wittgenstein. 2. ed. Rio de Janeiro: Jorge Zahar, 2000. p. 39-42. 
seu discípulo Platão já acreditavam no poder da razão e na contraposição de ideias como um meio de alcançar a verdade. Era precisa já a distinção entre seres submetidos a falsas interpretações do mundo e outros capazes de entender como as opiniões são construídas e percebidas.

Essas conquistas dos helenos foram decisivas para a história do Ocidente, para a história do pensamento e da vida política. Elas foram legadas aos romanos que as disseminaram pela Europa e para além dela; e, mais tarde, já na Modernidade, foram redescobertas pelos povos modernos, tornando-se fonte de inspiração para as relações entre os homens e entre eles e a realidade.

Desde então, a liberdade esteve sempre associada à possibilidade de esclarecimento, coerência e desvendamento da realidade. Acorrentados e sem acesso aos mecanismos a que estamos submetidos, somos apenas seres prisioneiros, entregues à ilusão e à manipulação. Então, desde o século VI a.C., os seres humanos têm procurado se dar conta do que constitui a realidade, fazendo valer seu direito de interpretar as imagens que nos chegam do mundo, debatendo e esclarecendo a respeito de sua justeza e veracidade. Não tem sido um processo fácil - os "fabricantes de imagens" têm procurado, ao longo dos séculos, impingir determinadas interpretações do mundo, tentando impedir que saiamos da caverna e tomemos consciência das manipulações de que se servem com esse objetivo.

\section{MODERNIDADE - A SOCIEDADE DOS INDIVÍDUOS CIDADÃOS}

Durante muito tempo, a cultura clássica esteve enterrada nos porões do medievalismo, sob a égide da hegemonia católica e da ignorância dos grandes textos antigos que debatiam a respeito da liberdade e das diferentes interpretações de mundo. Foram o humanismo e a laicidade, próprios do desenvolvimento cultural e artístico do renascimento, as condições para o retorno aos textos clássicos e a suas propostas. Tratava-se da autonomia da criatura em relação ao criador, diante do qual o ser humano se transformava também em criador. Uma mentalidade racionalista, cientificista e que pensava o ser humano como o centro da criação passa a conduzir a relação deste com os demais de sua espécie, com a natureza e até mesmo com o sagrado. A base dessas transformações encontrava-se entre os helenos, na sua concepção laica de Estado, de vida pública participativa, no humanismo e na postura especulativa que demonstravam em relação ao conhecimento. Foi nesse caldeirão de heranças que se constituiu uma das principais tendências da Modernidade - o individualismo.

Para se conceber como criador, autônomo e em permanente busca por si mesmo, o homem moderno se percebe único, com uma trajetória própria e particular com a qual ele se identifica essencialmente, rompendo os laços medievais com uma identidade baseada na religião, nos laços de parentesco e no localismo. Exemplo dessa atitude transformadora é a peça Romeu e Julieta, de William Shakespeare. Filhos de famílias rivais e inimigas, os jovens Romeu Montecchio e 
Julieta Capuleto se apaixonam, mas esse amor se vê impedido pelas inimizades e obrigações familiares. Tentando romper com esse grilhões, os jovens se casam em segredo. Na noite de núpcias, uma das cenas mais importantes da peça, Romeu se declara a Julieta dizendo que ele não é um Montecchio, mas sim o amor que sente por ela. Esse diálogo espelha bem a questão da identidade moderna - o ser humano se identifica não com sua herança familiar, com a região onde vive, mas com aquilo que existe de próprio em sua subjetividade - seus sentimentos, pensamentos, opiniões e anseios.

Explicando a importância dessa identidade do ser humano com suas ideias e opiniões e a necessidade, por isso mesmo, de contrapô-las com as dos demais, Karl Mannheim, citado por Abreu e Lima, escreveu mais tarde:

Não há a menor dúvida de que só o indivíduo é capaz de pensar. Não existe esta entidade metafísica denominada espírito grupal, que pensa acima das cabeças dos indivíduos, ou cujas idéias estes se limitam a produzir. Mas nem por isso se deve concluir que todas as idéias e sentimentos que motivam a conduta de um indivíduo tenham exclusivamente nele suas origens e possam ser adequadamente explicadas à luz da sua própria².

Não foi, entretanto, apenas o individualismo e esse sentimento de identidade pautado em nossa subjetividade que fez que as questões da liberdade e do conhecimento se tornassem tão importantes na Modernidade. Foi também o desenvolvimento do capitalismo, uma economia baseada na livre iniciativa, na busca pelo lucro e na propriedade privada dos meios de produção. Assim como o surgimento de um princípio de estado laico capaz de agregar as diferentes forças que se organizavam na sociedade, não só os proprietários de terras, como no passado, ou a elite religiosa, mas também os comerciantes e os militares, a burguesia sem sangue nobre e sem propriedades familiares. Todas essas transformações conduziram à quebra dos estreitos limites da sociedade medieval e aos anseios pela afirmação da individualidade, da liberdade, da participação na vida pública.

O resultado dessa busca foram as revoluções ocorridas entre os séculos XVIII e XIX, proclamadoras de liberdades, e como acontecimento emblemático, a proclamação dos Direitos do Homem e do Cidadão, em 1789, que, entre outras ementas que garantem a autonomia e soberania do cidadão, reconhece:

Ninguém pode ser molestado por suas opiniões, incluindo opiniões religiosas, desde que sua manifestação não perturbe a ordem pública estabelecida pela lei. [...] A livre comunicação das ideias e das opiniões é um dos mais preciosos direitos do homem. Todo cidadão pode, portanto, falar, escrever, imprimir livremente, respondendo, todavia, pelos abusos dessa liberdade nos termos previstos na lei ${ }^{3}$.

Tais objetivos e determinações, entretanto, não foram aceitos facilmente nem por unanimidade, e o estudo de Carlo Ginzburg sobre a Inquisição e o processo que esta impingiu ao moleiro Menocchio, pela liberdade com que ele interpretou os dogmas católicos à luz de livros de biologia que havia lido, é prova da intransigência com que a Igreja Católica encarava doutrinas não dogmáticas ${ }^{4}$. A resistência, quer dos monarcas, quer das autoridades religiosas, a essa nova
2. ABREU E LIMA, Fellipe de Andrade. Antropometria, individualismo e genialidade na tratadística do Renascimento Italiano. Revista Veredas, Caruaru, v. 2, n. 1-2, p. 11, 2009.

3. FRANÇA. Direitos do homem e do cidadão. 1789.

4. GINZBURG, Carlo. O queijo e os vermes. São Paulo: Companhia das Letras, 1998. 
proposta de vida social e de ordem pública se tornou mais acirrada à medida que se desenvolviam os meios de comunicação. Desde a invenção da prensa de Gutenberg até o aparecimento dos primeiros jornais diários, a Europa se armava contra a difusão de ideias que punha em risco sua hegemonia sobre a sociedade. A censura se institucionaliza, passando de iniciativa da Igreja Católica contra as heresias e a Reforma Protestante para uma medida a ser usada a fim de conter a dissidência, a crítica, a denúncia e a oposição, em um mundo que se democratizava e que o poder deixava de ser hereditário e vitalício.

\section{1. Opinião pública e meios de comunicação}

O desenvolvimento dos meios de comunicação ou da sociedade midiática, como a chamamos, se deu em razão de diferentes fatores. O primeiro deles é a revolução tecnológica que colocou à disposição de artistas e intelectuais novas formas de expressar suas ideias e de se expressarem para um grande público. O êxodo rural e o crescimento das cidades fizeram que nossa relação com a realidade fosse cada vez mais mediada pelos meios de comunicação - os jornais diários, as publicações, as revistas e, mais tarde, o rádio e a televisão -, que transformaram a vida cotidiana ao disciplinar os hábitos da população e a percepção que se tem da realidade, criando novas temporalidades.

A vida anônima das cidades também criou necessidades novas de integração entre grupos de pessoas que jamais conviveram, mas que dividem um mesmo espaço geográfico e social. Para esses grupos de origem, nacionalidade, formação e poder aquisitivo diferentes, ter uma mesma referência sobre a realidade passou a ser muito importante. Os meios de comunicação tiveram esse papel homogeneizador da vida urbana, que crescia a olhos vivos.

Outro fator responsável pelo desenvolvimento dos meios de comunicação foi a própria República instaurada a partir de 1789, com a Revolução Francesa. A partir de então, o poder, não sendo mais hereditário e vitalício como na Monarquia, incitou os partidos políticos e candidatos às eleições a recorrerem aos veículos de comunicação para chegarem ao público eleitor e alcançar certa popularidade. A aliança entre poder político e grandes meios de comunicação foi elemento essencial para as novas formas de governo que se instituíam.

5. ADORNO, Theodor W. Capitalismo Tardio ou Sociedade Industrial. In: $\mathrm{COHN}$, Gabriel. Sociologia: Theodor Adorno. São Paulo: Ática, 1986.

6. BOURDIEU, Pierre. O poder simbólico. 3. ed. Rio de Janeiro: Bertrand Brasil, 2000

7. ELIAS, Norbert. Escritos \& ensaios: Estado, processo, opinião pública. Organização de Federico Neiburg e Leopoldo Waizbort. Rio de Janeiro: Zahar, 2006, p. 124-125. 1 v.
Se esse fator fez alguns autores verem com desconfiança o desenvolvimento dos media e seu uso para a propaganda política, como Theodor Adorno ${ }^{5}$ e Pierre Bourdieu $^{6}$, outros veem na integração do público pelos media uma forma de organização e pressão política, como Norbert Elias. Afirma ele:

A opinião pública é, de certa maneira, um grupo de pressão não-organizado ou não especialmente muito organizado, fator potencial de influências nas decisões governamentais. [...] não é simplesmente uma sintonia de opinião de muitos seres humanos sobre uma questão do dia., particular e determinada, mas algo compreendido em contínua formação, um processo vivo que oscila em movimentos pendulares e que, no decorrer desse balanço, influencia as decisões que são tomadas em nome da nação ${ }^{7}$. 
Assim formou-se a sociedade midiática em que a relação entre as pessoas e a delas com a realidade se tornou cada vez mais mediada pelos meios de comunicação, quer na vida privada e particular, quer na ação política, na intervenção na sociedade e na vida pública em geral. Compreender como se forma a visão de mundo que o público constitui através dos medias passou a ser elemento importante para quem quer atuar social e politicamente. No embate entre tendências diversas e propostas conflitantes, a censura tornou-se elemento decisivo para a ascensão e manutenção de grupos no poder. Assim, a censura, que, no passado, havia sido instituída pela Igreja Católica através dos processos inquisitoriais, passa, na República, a ser prerrogativa dos grupos no poder.

\section{2. A censura e a guerra fria cultural}

A censura é tão antiga quanto a cultura humana pois somos uma espécie que tem uma forma muito peculiar de se relacionar com o mundo circundante que passa necessariamente pela elaboração simbólica de nossas experiências e resulta em um mundo subjetivo tão rico quanto particular. Esse universo simbólico constitui nossa história e nossa subjetividade. Mas, por outro lado, somos uma espécie bastante gregária que só sobreviveu às dificuldades impostas pelas transformações do meio em que vivemos porque conseguimos criar uma vida coletiva e uma forte sociabilidade. A soma dessa subjetividade simbólica e da vida intensa e coletiva que desenvolvemos resultou na criação da cultura que estabeleceu formas coletivas de existência e, ao mesmo tempo, de interpretações simbólicas do mundo que nos cerca e daquele que elaboramos com nossa subjetividade. O conflito entre esse mundo interno tão particular e único e a cultura hegemônica a qual pertencemos e que a nós se impõe faz que a censura seja um mecanismo psicológico e social para criar um caminho possível de sobrevivência de nossa interioridade e de participação na vida coletiva e na cultura.

Mas, se estivermos pensando na censura não desse ponto de vista do conflito entre eu e os outros, mas em uma instituição ligada ao poder dominante na sociedade, capaz de cercear ideias e comportamentos que sejam transgressores, então temos de remeter ao início da Modernidade, quando a Igreja Católica, através do Tribunal da Inquisição, combateu toda e qualquer ideia ou atitude que ameaçasse seus dogmas e seu código de conduta. Com a Inquisição, a censura a palavras, atos, ideias, comportamentos institucionalizou-se. Pessoas foram julgadas e condenadas, quer ao repúdio público (tendo de vestir-se com roupas de hereges), quer à morte por terem, segundo a doutrina cristã, desrespeitado os santos e autoridades eclesiásticas; professado heresias; desobedecido aos dogmas; divulgado ideias consideradas pagãs; manterem em seu poder livros prescritos. A Real Mesa Censória, instituída em 1769, que julgava o teor de livros e obras artísticas e as denúncias de comportamento sacrílego ou herético, era composta por representantes do Santo Ofício, vigários, representantes da Monarquia e professores e intelectuais de renome. Os Estados monárquicos iam aos poucos 
assumindo o comando das instituições censórias. Em Portugal, a partir de 1787, é instituída a Mesa da Comissão Geral sobre o Exame e Censura a Livros.

Vemos que, criada pela Inquisição, a instituição censória passou a ser um recurso do aparelho do Estado para coibir a disseminação de doutrinas consideradas heréticas. A monarquia combateu acirradamente os ideais republicanos, assim como, criada a República, serão perseguidos os autores monarquistas e, um pouco mais tarde, os socialistas. Já nesses primórdios de uma censura institucional, oficial, comandada por funcionários designados pelo poder, veremos que não há equidade nos princípios e critérios censórios. Na França, combatiam-se os ideais republicanos e as doutrinas protestantes; na Inglaterra, proibia-se o catolicismo, em defesa da Igreja Anglicana, cujo chefe era o rei. Assim, a censura passava a ser uma forma de defesa do status quo de cada governo estabelecido. Como afirma Karl Marx, em seu livro Liberdade de imprensa: "Ninguém luta contra a liberdade, luta-se contra a liberdade dos outros" ${ }^{8}$.

Mas é no século XIX que o socialismo se constitui em doutrina e luta política, fazendo os países republicanos, que antes lutaram contra a censura monarquista, começarem a interditar os textos considerados de apologia comunista e a perseguir seus autores, assim como os membros dos partidos que os apoiavam. Esse conflito explode no século XX quando se assiste ao que Frances Stonor Saunders ${ }^{9}$ chamou de Guerra Fria Cultural, ou seja, a defesa, de um lado, dos liberais republicanos e, de outro, dos comunistas, contra qualquer ideia que representasse os ideais contrários ou denúncias e críticas às suas políticas. A censura dos dois lados envolvidos representou elemento importante nessa época, em que governos totalitários, liberais-republicanos e comunistas procuravam exercer seu poder sobre o mundo e sobre os cinco continentes. A censura prévia institucionalizada e a vigilância cotidiana da imprensa escrita e falada tornou-se um recurso clássico. Quase sempre quando se fala em censura na atualidade, estamos nos referindo a um órgão de segurança criado por regimes autoritários para controle da produção simbólica, de forma a coibir denúncias, críticas e oposições.

8. MARX, Karl. Liberdade de imprensa. Porto Alegre: L\&PM, 2007, p. 46.

9. SAUNDERS, Frances Stonor. Quem pagou a conta? ACIA na Guerra Fria da cultura. Rio de Janeiro: Record 2008.

\section{3. Sociedade contemporânea e comunicação em rede}

Com o fim da União Soviética, principal manifestação do regime comunista propagado por Karl Marx, e com o desenvolvimento da comunicação em rede por computadores, assistimos à instauração de um processo novo integrando os diversos países e continentes, a globalização. Passamos a ter uma rede de comunicação global, interativa e participativa que alterou radicalmente a comunicação como a conhecíamos até então.

As transformações trazidas por essa sociedade globalizada que caracteriza a contemporaneidade são as seguintes: em primeiro lugar, as redes por computadores não são como as redes analógicas, isto é, unidirecionais, do centro para a periferia, as quais transformavam o público, predominantemente, em receptores passivos, sem a possibilidade de interagirem ou criarem conteúdos. Em especial, como as redes 
sociais que dão aos seus usuários larga margem de atuação comunicativa. O sucesso que elas têm obtido mostram a força dos anseios que nutria o público em geral.

Em segundo lugar, a comunicação em rede por computadores não é um serviço púbico, mas privado - são empresas particulares que oferecem globalmente conexão às redes. Isso implica umcusto alto para os usuários, além de uma infraestrutura tecnológica bastante desenvolvida para que a maioria da população possa aceder a esse serviço. Isso resulta em uma outra forma de exclusão social - há cidadãos com maior ou menor inserção nas redes, assim como países com melhores condições de bom funcionamento dos serviços de comunicação e outros com menores possibilidades. Uma topografia se cria entre usuários estabelecendo diferentes níveis de inclusão digital.

Em terceiro lugar, o controle dessas redes não é mais nacional. Na sociedade globalizada, os Estados têm pouco poder sobre a expansão das redes que se desenvolvem com o apoio e cumplicidade dos Estados nacionais, mas que dependem de empresas com sede no exterior.

Em quarto lugar, o desenvolvimento tecnológico dos programas, sistemas e máquinas faz que seja difícil acompanhar a complexificação da comunicação digital, o que exige sempre maiores investimentos, quer dos Estados, quer dos usuários. A obsolescência dos equipamentos põe em risco as informações, os conteúdos e a capacidade do usuário de permanecer conectado e atuante. Dessa forma, tornamo-nos, cidadãos, empresas e países cada vez mais dependentes de investimentos e desenvolvimento tecnológico.

Em quinto lugar, políticas públicas educacionais são programadas para alfabetizar usuários ao correto uso das novas máquinas, havendo problemas sérios de comunicação para quem se mantiver a distância da globalização tecnológica.

Como a invenção da eletricidade, a instituição da comunicação em rede globalizada criou um processo social em cascata, exigindo que qualquer intervenção na sociedade exija conhecimento, habilidade, recursos materiais, humanos e tecnológicos para ter qualquer eficácia, desde uma barraca de vendas ambulante até grandes conglomerados comerciais, dos processos educativos ao jornalismo, da saúde à segurança nacional. Portanto, integrar-se na sociedade através de processos comunicacionais, hoje, ocupa grande parte de nosso planejamento econômico, político e social. Para completar essas dificuldades, implantou-se, nessa sociedade globalizada, um capitalismo neoliberal que pretende a redução do papel do Estado Nacional na solução de problemas sociais e a hegemonia do mercado nas decisões políticas. Isso significa que haverá pouca intervenção do Estado com a intenção de minorar as dificuldades da população em geral, quer com a inserção da população na comunicação em rede, quer com os investimentos econômicos na proteção aos mais desfavorecidos.

Por outro lado, no que concerne ao controle da opinião e à publicidade, especialmente aquela que diz respeito às campanhas eleitorais nas sociedades republicanas, novas formas de censura e interdição se estabelecem. Diferentes países, diversas culturas posicionam-se de maneira distinta nesse universo globalizado da comunicação. Como controlar as redes sociais que permitem a inserção de conteúdos 
de forma instantânea, a interação em tempo real e uma liberdade inusitada, além de uma propagação de informações em um ritmo jamais visto anteriormente. Novos mecanismos de fiscalização e responsabilização começam a surgir e a se legitimar. Contra eles, entretanto, atua uma nova cultura - a hacker - que, como a contracultura dos anos 1960, busca opor-se, fazer frente e desenvolver meios de resistência à hegemonia da cultura tecnológica globalizada. Desde os neoludistas, que se revoltam contra as transformações materiais e produtivas dos novos meios digitais, até os jovens tecnólogos, que rejeitam o domínio tecnológico das grandes corporações, dissemina-se um espírito de resistência e provocação que faz uso do que chamamos hoje de terrorismo digital - ataques a sistemas, destruição de informações, quebra de dados sigilosos. Um dos casos mais emblemáticos é o de Edward Joseph Snowden, analista de sistemas da Central Intelligence Agency (CIA), dos Estados Unidos, que distribuiu a jornais ingleses informações sigilosas dos programas com os quais trabalhava. Em razão disso, hoje, na Inglaterra, julga-se o pedido de extradição de Snowden para os Estados Unidos.

A defesa do nacional adquire nova importância diante da comunicação em rede - informações chegam de todos os lados e de diversas fontes. Qual a importância do que nos é próximo? O que está longe e o que está perto? O que nos diz respeito diretamente e diante do quê somos apenas voyeristas? Novos parâmetros e novas referências passam a ser importantes e a servirem de balizas para nossa forma de estar no mundo.

Claro que as possibilidades de manipulação do público se tornam cada vez maiores - perdemos as referências daquilo que as informações indicam. O mundo se torna cada vez menor - estamos, segundo as mais recentes teorias, a seis cliques de qualquer pessoa no planeta, mas, paradoxalmente, nossas experiências de vida e o conhecimento da realidade são cada vez mais mediados pelos meios de comunicação. Como transformar informação em conhecimento?

\section{CONCLUSÃO - O QUE É DEMOCRATIZAR AS MÍDIAS?}

As respostas às questões propostas neste texto exigem que retornemos ao início de nossa apresentação - à Caverna de Platão. A história desses séculos que nos separam de Atenas e da invenção da democracia e da vida pública participativa tem criado cada vez mais obstáculos para a liberdade dos prisioneiros que, acorrentados, são expostos às projeções de um mundo que eles desconhecem. Podemos dizer que a caverna se tornou mais profunda e que as fontes de imagem se multiplicaram ao infinito. Como, então, garantir a possibilidade de nos comunicarmos com a realidade; como valorizar nossa própria percepção; como contrapormos ideias e visões de mundo, apropriando-nos daquilo que pode ser considerado real? Acreditamos que isso exige o que chamamos de democratização das mídias, ou seja, a possibilidade de ascendermos e sairmos da caverna, apropriando-nos dos meios, das informações e das técnicas de produção e reprodução das imagens. A educação é o meio mais eficaz para 
chegar a esse objetivo - é fazendo a comunicação se tornar elemento essencial da educação, do conhecimento e da informação que poderemos nos libertar dos grilhões da passiva recepção de mensagens.

Assim, terminamos este artigo apontando aquilo que consideramos como democratização dos meios de comunicação.

- Criar mecanismos jurídicos de controle do uso da mídia pelo Estado procurando evitar que governantes façam uso intensivo dos meios de comunicação na defesa de seus próprios interesses, é preciso criar regras que estabeleçam os limites de um uso equânime dos meios de comunicação pelos que já são governo e por aqueles que pretendem sê-lo.

- Administrar com transparência a distribuição de concessões de uso dos meios de comunicação - é preciso lembrar sempre que a comunicação é um serviço público e que as empresas que fazem uso de concessões para se responsabilizar por isso devem ter em seus objetivos os interesses públicos e não apenas os próprios. Estabelecer limites nítidos entre público e privado.

- Ampliar a infraestrutura tecnológica, tornando o país autônomo em termos comunicacionais - é necessário que, no mundo globalizado, um Estado possa suprir sua necessidades essenciais para participar dessa orquestra planetária. A dependência tecnológica pode levar a neocolonialismos. Investimentos em comunicação são requisitos de autonomia, independência e autogestão.

- Garantia, à população e ao público em geral, de acesso aos meios de comunicação para que possam intervir, se expressar e interagir com o próximo e o distante. Muito pior do que evitar confrontos é dar a impressão de que eles não existem. O confronto permite que se tome conhecimento da diversidade de opiniões, um requisito necessário para não se considerar apenas uma opinião dominante dado de realidade. A pluralidade e a diversidade dependem disso.

- Planejar a alfabetização mediática como elemento intrínseco da educação, fornecendo elementos para que o público se assenhore dos mecanismos de produção de imagens e informações, rompendo com uma atitude ingênua diante dos meios de comunicação. É preciso desconstruir as mensagens, desvendando os processos de criação e chegando a seu autor e, assim, à intencionalidade do que está sendo informado.

- Fortalecer a comunicação nacional, regional, local, informal, alternativa, mesmo considerando que a informação é uma mercadoria e que está sujeita, no mundo capitalista, às regras de mercado. Nas formas de comunicação informais está um olhar para o mundo mais desinteressado e mais público.

- Favorecer a expressão artística - tanto a erudita como a popular - porque é experienciando as emoções e as sensibilidades que nos tornamos mais aptos a entender as metáforas, as mensagens complexas. A arte expressa sempre de forma mais sensível o seu tempo e aquele que se anuncia. 


\section{REFERÊNCIAS BIBLIOGRÁFICAS}

ADORNO, Theodor W. Capitalismo Tardio ou Sociedade Industrial. In: COHN, Gabriel. Sociologia: Theodor Adorno. São Paulo: Ática, 1986.

ABREU E LIMA, Fellipe de Andrade. Antropometria, individualismo e genialidade na tratadística do Renascimento Italiano. Revista Veredas, Caruaru, v. 2, n. 1-2, p. 1-22, 2009.

GREENBLATT, Stephen. A virada: o nascimento do mundo moderno. São Paulo: Companhia das Letras, 2012.

BOURDIEU, Pierre. O poder simbólico. 3. ed. Rio de Janeiro: Bertrand Brasil, 2000.

BURKE, Peter. Uma história social do conhecimento: de Gutenberg a Diderot. Rio de Janeiro: Zahar, 2003. 1 v.

CHAUNU, Pierre. A civilização da Europa clássica. Lisboa: Estampa, 1987. v. 1.

ELIAS, Norbert. Escritos \& ensaios: Estado, processo, opinião pública. Organização de Federico Neiburg e Leopoldo Waizbort. Rio de Janeiro: Zahar, 2006. v. 1.

FRANÇA. Direitos do homem e do cidadão. 1789.

GINZBURG, Carlo. O queijo e os vermes. São Paulo: Companhia das Letras, 1998.

KOFLER, Leo. Contribución a la historia de la sociedad burguesa. Buenos Aires: Amorrortu, 1974.

MARX, Karl. Liberdade de imprensa. Porto Alegre: L\&PM, 2007.

PLATÃO. A Alegoria da caverna: A Republica, 514a-517c. In: MARCONDES, Danilo. Textos básicos de Filosofia: dos Présocráticos a Wittgenstein. 2. ed. Rio de Janeiro: Jorge Zahar, 2000. p. 39-42.

SAUNDERS, Frances Stonor. Quem pagou a conta? A CIA na Guerra Fria da cultura. Rio de Janeiro: Record, 2008.

STAROBINSKI, Jean. 1798: os emblemas da razão. São Paulo: Companhia das Letras, 1988.

TOYNBEE, Arnold Joseph. A herança dos gregos. Rio de Janeiro: Zahar, 1984. 